$\xi=1$ 国

\title{
Optimal Control Signal for an EEG Based Casual BCI
}

\author{
Satyajit Sen Purkayastha ${ }^{1}$, V K Jain ${ }^{2}$, H K Sardana ${ }^{3}$ \\ ${ }^{1}$ Electrical and Electronics Engineering, Amrapali Institute of Technology and Science, Haldwani, INDIA \\ ${ }^{2}$ Electrical and Instrumentation Engineerng, SantLongawal Institute of Engineering and Technology, Longowal, Sangrur, INDIA \\ ${ }^{3}$ HRD, Central Scientific Instruments Organisation, Sector 30, Chandigarh, INDIA \\ *Corresponding AuthorE-mail: ${ }^{1}$ sen.satyajit@rediffmail.com, ${ }^{2}$ vkjain27@yahoo.com, ${ }^{3}$ hk_sardana@csio.res.in
}

\begin{abstract}
BCI (Brain computer interface) is a control and communication system which allows electrophysiological activity to control a computer or a peripheral device directly, without taking the natural route of peripheral nerves and muscles. The prime motive behind developing BCI technology was its ability to act as the only interactive link for people disabled by amyotrophic lateral sclerosis (ALS), cerebral palsy, spinal cord injury, stroke and similar neuromuscular disorders of high severity. However in the last decade, a gradual shift in BCI end-users from patients to casual (healthy) individuals has increased significantly. Because of this shift, BCI community has recognized the need for EEG based casual BCI to be more efficient and user friendly, keeping in mind the customized needs of healthy (Casual) user. So for increasing the performance of such BCIs, the selection of optimal control signal plays a very significant role. Hence, in this work, we evaluate various EEG control signals (CS) in accordance with considerations relevant to user-friendliness of casual BCIs and point up their neuro-physiological origins as well as their effectiveness in current applications. Finally, we recommend a set of parameters for selection of optimal EEG based control signal for casual BCIs and the best suitable option available among the present day control signals.
\end{abstract}

Keywords: Brain computer Interface, Optimal control signal, BCI, EEG, SSVEP, SSEP, SSSEP, ASSR, P300, Motor Rhythms, Sensorimotor rhythms, Slow cortical potentials, Non motor cognitive task, User friendly.

\section{Introduction}

The purpose of an EEG based casual BCI is to interpret the user's intentions by means of monitoring electrophysiological activity non-invasively. As established, EEG is the summation of the postsynaptic potentials produced by hundreds and thousands of neurons having identical radial orientation [1]. These signals are the resultant of a range of parallel processes taking place during a cognitive task, larger fraction of which is still inexplicable and their exact points of origin are still unrevealed. Nevertheless, physiological phenomena of few signals have been successfully decoded, which could be modulated by a user enabling the BCI systems to interpret their intentions. Hence, these EEG signals act as control signals (CS) in various BCIs, including "Casual end user" BCI. The user-friendliness is a major consideration for the Casual BCIs, but the phrase "user-friendly" seems a simple enough perception to understand; however like so many vivacious concepts; it skids out of the turf when we focus the research microscope on it. The difficulty of defining the concept of "Userfriendly" results from the fact that it largely has two performance indices, the ease of performing the process and the utility of the final outcome of the process. So far, the concept of userfriendliness has been applied to both former and later indices quite haphazardly. We call a BCI application user-friendly if its features can be used easily by a BCI trainee, meanwhile we also call it user-friendly if the person using the BCI application provides positive feedback to us once we get the application up and running. Therefore, no set criterions are fixed till date, for the user friendliness of casual BCIs.
In this paper, Section II details the neuro-physiological origin of various EEG control signals relevant to casual BCI. Section III evaluates the effectiveness of these control signals in current applications; Section IV proposes the major considerations for "user-friendliness" of CasualBCI; Section V assesses the utility of various EEG control signals focusing on the "User-friendly" perspective. Finally, section VI discusses the results and presents the optimal EEG control signal for the context.

\section{Physiological Origin of EEG Based BCI Control Signals}

Control signals for an EEG based Casual BCI is obtained noninvasively and could be categorized into two main sections, Evoked signals section and Spontaneous signals section [2, 3]. In brain research, it is a widespread tactic to evaluate the EEG signals in response to how a lone neuron or a set of neurons reacts, when subjected to different stimuli. Hence, Evoked signals are defined as the changes in the normal ongoing EEG activity, due to the introduction of specific stimulations to the user. These signals are widely known as Evoked Potentials (EP). Whereas, spontaneous signals are the measure of the EEG on the user's scalp and are called spontaneous as these signals are associated with usual and regular activities of living brain which goes on continuously. The significant control signals in evoked signals section are Steady State Evoked Potentials (SSEP) and P300 [2,3], whereas within the category of spontaneous signals section, the most used control signals are sensorimotor rhythms. Slow cortical potentials and non-motor cognitive signals. 


\section{A. Steady State Evoked Potentials (SSEP):}

These are brain potentials which materialize when the user is introduced to a periodic stimulus such as a flickering picture or a sound modulated in amplitude. Here, the brain activity has the same frequency as the stimulating frequency. In other words, the rate of stimulation will be followed by the frequency of the response, and thereby serve as a frequency signature in the brain signal $[4,5,6]$. Nowadays, diverse kinds of SSEP are used as control signals like: Steady State Visual Evoked Potentials (SSVEP) [4, 7, 8, 9,10], Somatosensory SSEP (SSSEP) [6] and auditory SSEP (ASSR) [5].

(i). Steady State Visual Evoked Potentials (SSVEP): These are the resultant evoked potentials triggered by visual stimulus with a frequency range of $6 \mathrm{~Hz}$ to $25 \mathrm{~Hz}$, which has substantial intersubject variability [11]. When a flashing stimulus is used, the SSVEP exhibits a sinusoidal waveform with fundamental frequency similar to the flashing frequency of the stimulus, but if the stimulus is a pattern then SSVEP occurs at their harmonics with a reversal rate [12].The major cause for using SSVEP as a control signal is due to the facts that the amplitude and phase of SSVEP are highly responsive to stimulus parameters such as repetition rate, spatial frequency and modulation depth (13) Moreover in extended interval of time, the discrete frequency components remain closely constant for SSVEP components, both in amplitude and phase [13]. In addition SSVEPs are also less susceptible to artifacts produced by blinks, eye movements and electromyographic noise contamination $[14,15,16]$.

(ii). Somatosensory Steady State Evoked Potentials (SSSEP): These are evoked potentials generated at primary and secondary somatosensory cortices as a result of tactile stimulation caused by repeated pressure against the skin $[17,18,19]$. These potentials are recorded by applying vibratory stimuli of variable modulation frequencies and exhibit the greatest signal to noise ratios at modulation frequencies of $26 \mathrm{~Hz}$ [20]. Even broader maximum in the frequency range could be generated between 21 and $27 \mathrm{~Hz}$ $[17,21,22]$. These frequencies elicit the largest SSSEP amplitudes and accordingly are utilized as a control signal for BCIs.

(iii). Auditory Steady State Rhythms (ASSR): These are the responses to auditory stimulations produced by amplitude modulated tones $[23,24]$. These oscillatory responses are generated at auditory cortex, even though modulated by thalamocortical systems $[25,26]$ and the optimal frequencies for modulation are in the $40 \mathrm{~Hz}$ range [19, 22, 27, 28, 29, 30, 31]. The worth of ASSR as control signal is still not apparent as the reason of power increment at $40 \mathrm{~Hz}$ is vague [29]. However, the steadystate responses in the auditory cortex reflects sensory processing through integration of auditory signals over time within the primary auditory cortex $[24,32]$ and thus provides supports the use of ASSR as a control signal.

\section{B. P300 Evoked Potentials:}

These potential consists of a positive waveform appearing approximately $300 \mathrm{~ms}$ after a rare and relevant auditory, visual or somatosensory stimulus [33]. It is generated through the "oddball" paradigm, where the user is requested to focus on a random sequence composed of two kinds of stimuli, one being less frequent than the other [10]. If the rare stimulus is relevant to the user, its appearance triggers a P300 in the user's EEG, which is located in the parietal areas. It has been established that, lesser the probability of occurrence of a stimulus, the larger is the amplitude of the response peak $[34,35]$. This property affirms the use of P300 evoked potential as the control signal.

\section{Motor and Sensorimotor Rhythms:}

Rhythms originating at motor cortex as a result of cerebral activity and motor activity comprise this category. These rhythms consist of oscillations in the brain activity in the frequency band $(7-13 \mathrm{~Hz})$ and $(13-30 \mathrm{~Hz})$, which are generally known as $\mathrm{Mu}$ and Beta rhythms respectively [10]. These rhythms are used to control BCIs as one could be trained to generate these modulations voluntarily $[36,37]$. The amplitude could also be varied when cerebral activity is associated with any motor task [38, 39]. Similar modulation patterns are observed when a mental dummy run of a motor act without any apparent motor output is done [38]. Besides, two kinds of amplitude modulation are possible with these rhythms namely event-related desynchronization (ERD) and event-related synchronization (ERS). In ERD amplitude suppression of the rhythm occurs whereas ERS exhibits amplitude enhancement, hence these are excellent control signals for a BCI.

\section{Slow Cortical Potentials (Scp):}

These are slow EEG voltage shifts those continue for hundreds of milliseconds to several seconds [10]. They fit into the fraction of EEG signals below $1 \mathrm{~Hz}$ and are tied to changes in the levels of cortical activity. Positive SCPs match with decreased activity in individual cells whereas Negative SCPs associate with increased neuronal activity [40]. As it is possible to make variations either positive or negative by training, hence SCP could be used in controlling a BCI [41, 42].

\section{E. Non-Motor Cognitive Signals:}

These are the signals generated while performing mental tasks like multiplication, object rotation, alphabets composition or counting. As established,left hemisphere of brain processes the analytic, verbal and serial information whereas right hemisphere processes the visual-spatial information [77]. Hence these signals exhibit hemispheric specialization and are easily recognized using power spectrum or Autoregressive Coefficients of the EEG signal [43] and therefore could be utilized in controlling BCIs.

\section{Effectiveness of Control Signals in Current BCIS}

\section{A. SSEP for BCI:}

SSEPs are entirely measurable with non-invasive methods and the mental tasks associated with the recording procedure are mostly effortless. This makes SSEPs a much anticipated collection of brain signals. A SSEP-BCI is based on a less demanding mental strategy of selective attention, which makes this system more efficient and fast [44].

(i). SSVEP for BCI: SSVEP control signal is used in two different ways [45], in first; the users are trained to control the strength of their SSVEP, where binary control actions are possible. For example, a device can be turned on or off, moved up or down, etc. These willfully controlled changes in SSVEP results in controlled actions. Whereas, in the second method, multiple SSVEPs are used as control and the user requires very little training, in view of the fact that the system capitalizes on the naturally occurring responses. For example, multiple frequencies via virtual keys on a screen are displayed and the user decides on the favouredkey by just staring on it, which in turnis coupled to a control action. In first method, users perform 200 trials each without training with $92 \%$ classification accuracy (average) in a binary choice system and 28.5 selections per minute could be achieved. However, a major boost could be achieved in classification accuracy by using the third harmonics and Gaze shifting, but the later is not necessary for some users and at the 
same time relies heavily on the task and display [46, 47, 48, 49]. Some of the systems could exhibit up to 64 visual stimuli and a communication rate of $10-12$ words/min as established by Sutter et al $[3,50]$. Few of the systems as proposed by Cheng et al. with 13 flickering light targets could exhibited an average classification accuracy of $77.3 \%$ and show a maximal capability of 54.46 bits/min [51]. Likewise the online system of Nielsen et al. containing 9 squares, each flickering at a different frequency exhibits classification accuracy (average) of $79.7 \%$ along withcapability of selecting 9.3 characters per minute [52]. These results indicate the possibility of driving a multi-class SSVEPBCI.

(ii). SSSEP for BCI: SSSEP system of Muller-Putz et al demonstrates a 2-class BCI where stimuli are applied to the index fingers and the subject have to focus on eitherof the finger tips. LDA (Linear Discriminant Analysis) is used to detect thisraise of the elicited SSSEP and the online performances may vary from $57.5-83.1 \%$ per subject per day. However few considerations have to be taken care of for using SSSEP; firstly the human sensory system has specific resonance range and hence scrutiny of anoptimal frequency range has to be done $[13,21]$. Secondly, few subjects may have concentration problems and may not focus in the entire session of 160 trials [6]. However, the advantages are the possibility to avoid eye muscle control problems and its stability. Furthermore, they are measurable on a single trial basis.

(iii). ASSR for BCI: ASSR signal has not been used for driving a BCI yet however the results of Hill et al.[53] implies the prospect ofutilizing auditory stimulation and focus to drive a BCI with no previous training. Hereresponse of auditory stimuli modulates ERP in a reliable manner and hence a single trial is sufficient. In this research ERP was used, but in both cases of ERP and ASSR the amplitude could be modulated by attention, which is an indication that the report of Hill et al. can be used as a base for future ASSR-BCI research. Future research should definitely be based on the fact that patients may not be able to shift gaze in many cases and hence it is a significant motivation to add ASSR$\mathrm{BCI}$ to the palette of available BCI paradigms.

\section{B. P300 for BCI:}

A matrix of $6 \times 6$ displaying numbers, symbols, commands, alphabets is generally used for P300 based BCIs. It was first proposed by Donchin et al. where either a row or a column flashes in every $125 \mathrm{~ms}$ for 12 times. The subjectfocuses on the preferred option in the matrix and counts the number of times the preferred option flashes. The parietal cortex EEG is digitised and then the average response to a row and a column is weighed up, plus for each choice the P300 amplitude is found. The P300 response is unusual for preferred option and the BCI make use of this outcome to decide the user's intention. The communication rate achieved is one word per minute with no initial training requirements. However, P300 changes response to conditioning protocols $[3,55,56,57,58,59]$ and it is also time variant. So, in long term, P300 might get habituated in [35] causing deterioration or improvement in BCI performance.

\section{Motor and Sensorimotor Rhythms for Bci:}

These rhythms are very useful for the design of endogenous BCIs as these rhythms do not need any actual movement [39], however controlling SMR is quite complicated as motor imagery is difficult for most users. This system demands user training, because users need tocarry out motor imagery from where related SMRis recorded and later classified. In the end, feedback is provided to the user in the audio or visual form, but its effectiveness isconsiderablylow in spite of wide usage, so Hwang et al. [60] suggested a method where the user is presented with real-time feedback in the form oftheircortical activity. Wadsworth [61], Berlin [62] or Graz [63] BCIs also uses SMRand 20-25 bits/min
ITR (information Transfer Rate) have been successfully achieved [64]. Moreover both synchronous mode and asynchronous mode operations are possible in these BCIs.

\section{Slow Cortical Potentials (SCP) for BCI:}

Users can generate and regulate voluntary changes in SCP using a thought-translation device (TTD)[65]. Generally SCP is extracted by filtering followed by EOG removal and then it is presented to the user in the form of a visual feedback from a computer, where the screen has two options at the top and the bottom. This choice between options consumes almost 4 seconds and the final selection of option is displayed in various ways. Success in training depends on various aspects like psychological and physical condition of user, motivation, sleep quality, pain, mood and social situations, etc $[65,66]$. Moreover the users skill to modulate SCP effects the performance and hence the initial trial decides the importance of SCPs as a control signal $[65,67]$. Accuracy rates vary from $65 \%$ to $90 \%$ but longer training is also required.

\section{E. Non-motor Cognitive Tasks for BCI:}

Mental tasks such as mental rotation of shapes, visual counting, music imagination,mental generation of words, mental mathematical computations, etc. are used to drive BCIs $[2,43,68,69,70,71]$. All these tasks create specific EEGpatternsin specific locations in cortex which make them distinct from each other. A motor imagery BCI system based on imagination of cube rotation, arithmetic tasks and word concatenationwas developed by Millan at el $[72,73]$. Similarly Penny at el. developed a motor imagery system that works together with non-motor cognitive tasks [74,75] whereas Curran et al. utilized auditory imagery, imageryofmotor tasks, and imagery spatial navigation for BCI driving [76]. These systems could recognize and analyze spontaneous EEG with $70 \%$ accuracy and $5 \%$ errors. Besides, the users could be trained in a short period of 5 days.

\section{Considerations for a Casual BCI to be "User Friendly"}

For a Casual BCI to be user friendly there are primarily two performance indices explicitly - the ease of performing the process and the usability of final outcome of the process, hence the major necessities are formulated keeping in mind the following:

A). Convenience and comfort: For user friendly category of Casual BCIs, a major factor that should be considered is that the target user group may not necessarily be dependent on the system for vital activities. Moreover, if the usage of the system demands some inconvenience in the form of medical alterations (invasive systems), time consumption in the form of system preparation / training or increased level of fatigue after the usage, then the chances of utility by the target users will reduce, diminishing the system's user friendliness.

B). Stable system performance: Any system is considered better if it exhibits stable system performance and for Casual BCI this takes the form of interpreting the thoughts or instructions of the user in a proficient way and faithfully reproducing the output in minimum possible timeframe.

C). Cost factor: Any system with minimal cost has more likelihood of satisfying consumers provided the above two conditions are fulfilled. 


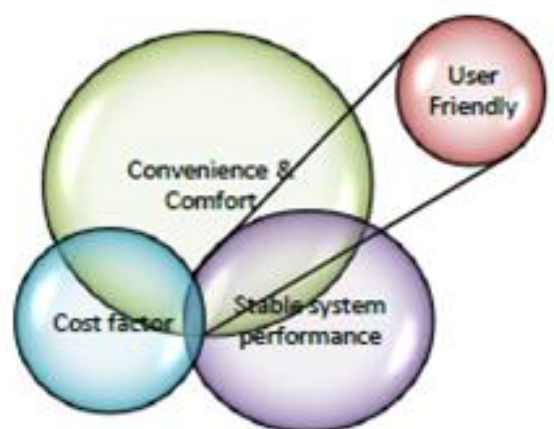

Fig. 1: Representation of necessary conditions for becoming "user friendly" BCI:

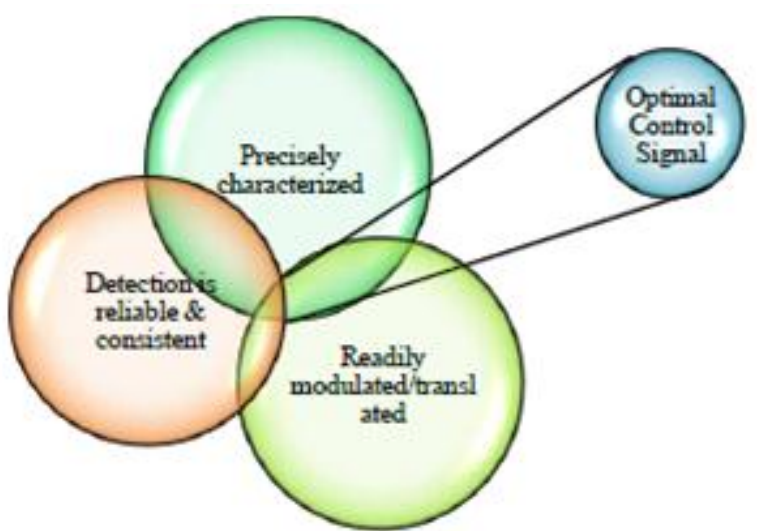

Fig. 2: Representation of necessary conditions for optimal control signal

\section{Assessment of Various Control Signals for a User Friendly BCI:}

All the considerations for the "user friendly" casual BCI are directly or indirectly dependent on the selection of the control signal for driving the BCI and an optimal control signal should have the following attributes:

A). Precisely characterized: Optimal control signal should be precisely characterized for an individual as it would act as the lone source of information for the system. More characterized the control signal more is the controllability.

B). Readily modulated or translated: Optimal control signal should be readily modulated or translated for the efficient conversion of the user's intention and results in better system performance.

C). Detection is reliable and consistent: Optimal control signal should be detected consistently and reliably as it would directly influence the stability of the system, more reliable and consistent control signal will have more stable output.

So, keeping in view the necessary conditions for a "user friendly" Casual BCI and the mandatory attributes of optimal control signal, the specific and elaborate considerations for selecting the optimal control signal for a user friendly Casual BCI has been formulated in the form of a chart, which not only provides the ideal value of all the considerations for the optimal control signal of a "user friendly" BCI but also provides the comparative status of all the other EEG control signals.

Table 1: Comparative chart of optimal and major control signals used in BCIs

\begin{tabular}{|c|c|c|c|c|c|c|c|c|}
\hline Signals & \multirow[t]{2}{*}{ SSVEP } & \multirow[t]{2}{*}{ SSSEP } & \multirow[t]{2}{*}{ ASSR } & \multirow[t]{2}{*}{ P300 } & \multirow{2}{*}{$\begin{array}{l}\text { Motor/Sensorimot } \\
\text { or Rhythms }\end{array}$} & \multirow[t]{2}{*}{ SCP } & \multirow{2}{*}{$\begin{array}{l}\text { Non-motor } \\
\text { cognitive task }\end{array}$} & \multirow{2}{*}{$\begin{array}{c}\text { Optimal } \\
\text { control } \\
\text { Signal for } \\
\text { user friendly } \\
\text { BCI } \\
\end{array}$} \\
\hline $\begin{array}{c}\text { Consideration } \\
\mathrm{s}\end{array}$ & & & & & & & & \\
\hline $\begin{array}{l}\text { Physiological } \\
\text { phenomena }\end{array}$ & $\begin{array}{l}\text { Brain } \\
\text { potential } \\
\text { generated } \\
\text { because of } \\
\text { visual } \\
\text { stimulus }\end{array}$ & $\begin{array}{l}\text { Brain } \\
\text { potential } \\
\text { generated } \\
\text { because of } \\
\text { tactile } \\
\text { stimulus }\end{array}$ & $\begin{array}{l}\text { Brain } \\
\text { potential } \\
\text { generated } \\
\text { because of } \\
\text { auditory } \\
\text { stimulus }\end{array}$ & $\begin{array}{l}\text { Brain } \\
\text { potential } \\
\text { generated at } \\
\text { about } 300 \\
\text { ms because } \\
\text { of } \\
\text { interspersed } \\
\text { infrequent } \\
\text { and } \\
\text { frequent } \\
\text { stimuli. }\end{array}$ & $\begin{array}{l}\text { Increase/ decrease } \\
\text { in mu and beta } \\
\text { rhythms because of } \\
\text { motor activities }\end{array}$ & $\begin{array}{l}\text { Slow } \\
\text { voltages } \\
\text { shift in the } \\
\text { EEG which } \\
\text { is inversely } \\
\text { related to } \\
\text { cortical } \\
\text { activity. }\end{array}$ & $\begin{array}{l}\text { Signals } \\
\text { generated } \\
\text { while } \\
\text { performing } \\
\text { mental tasks }\end{array}$ & $\begin{array}{l}\text { Brain } \\
\text { potential } \\
\text { which could } \\
\text { be generated } \\
\text { easily and } \\
\text { can be } \\
\text { precisely } \\
\text { characterize } \\
\text { d }\end{array}$ \\
\hline $\begin{array}{l}\text { Types of } \\
\text { inputs used } \\
\text { for } \\
\text { generation of } \\
\text { control signal }\end{array}$ & Evoked & Evoked & Evoked & Evoked & Spontaneous & $\begin{array}{l}\text { Spontaneou } \\
\mathrm{s}\end{array}$ & Spontaneous & Spontaneous \\
\hline $\begin{array}{l}\text { Stimulus } \\
\text { required or } \\
\text { not }\end{array}$ & Required & Required & Required & Required & Not required & $\begin{array}{l}\text { Not } \\
\text { required }\end{array}$ & Not required & Not required \\
\hline $\begin{array}{l}\text { Stimulus } \\
\text { Frequency }\end{array}$ & $\begin{array}{l}6 \mathrm{~Hz} \text { to } \\
25 \mathrm{~Hz}\end{array}$ & $\begin{array}{l}21 \mathrm{~Hz} \text { to } \\
27 \mathrm{~Hz}\end{array}$ & $40 \mathrm{~Hz}$ & $\begin{array}{l}6 \mathrm{~Hz} \text { to } 40 \\
\mathrm{~Hz}\end{array}$ & NA & NA & NA & $\begin{array}{l}\text { Stimulus } \\
\text { should not be } \\
\text { required }\end{array}$ \\
\hline $\begin{array}{l}\text { Location of } \\
\text { origin of } \\
\text { control signal }\end{array}$ & $\begin{array}{l}\text { Occipital } \\
\text { cortex }\end{array}$ & $\begin{array}{l}\text { Primary and } \\
\text { secondary } \\
\text { somatosensor } \\
\text { y cortices }\end{array}$ & $\begin{array}{l}\text { Auditory } \\
\text { cortex }\end{array}$ & $\begin{array}{l}\text { Parietal } \\
\text { Cortex }\end{array}$ & Sensorimotor cortex & $\begin{array}{l}\text { Central, } \\
\text { frontal and } \\
\text { parietal } \\
\text { cortex }\end{array}$ & $\begin{array}{l}\text { Cerebral } \\
\text { Cortex }\end{array}$ & $\begin{array}{l}\text { Easily } \\
\text { traceable }\end{array}$ \\
\hline $\begin{array}{l}\text { Training } \\
\text { required or }\end{array}$ & $\begin{array}{l}\text { Not } \\
\text { required }\end{array}$ & Not required & $\begin{array}{l}\text { Not } \\
\text { required }\end{array}$ & $\begin{array}{l}\text { Not } \\
\text { required }\end{array}$ & Required & Required & Required & Not required \\
\hline
\end{tabular}




\begin{tabular}{|c|c|c|c|c|c|c|c|c|}
\hline not & & & & & & & & \\
\hline Approach & $\begin{array}{l}\text { Exogenous } \\
\text { BCI }\end{array}$ & $\begin{array}{l}\text { Exogenous } \\
\text { BCI }\end{array}$ & $\begin{array}{l}\text { Exogenous } \\
\text { BCI }\end{array}$ & $\begin{array}{l}\text { Endogenou } \\
\text { s BCI }\end{array}$ & Endogenous BCI & $\begin{array}{l}\text { Endogenou } \\
\text { s BCI }\end{array}$ & $\begin{array}{l}\text { Endogenous } \\
\text { BCI }\end{array}$ & Endogenous \\
\hline Dependency & Dependent & Dependent & Dependent & Dependent & Independent & $\begin{array}{l}\text { Independen } \\
\mathrm{t}\end{array}$ & Independent & Independent \\
\hline $\begin{array}{l}\text { Synchronous/ } \\
\text { Asynchronou } \\
\text { s }\end{array}$ & $\begin{array}{l}\text { Synchronou } \\
\mathrm{s}\end{array}$ & Synchronous & $\begin{array}{l}\text { Synchronou } \\
\mathrm{s}\end{array}$ & $\begin{array}{l}\text { Synchronou } \\
\mathrm{s}\end{array}$ & $\begin{array}{l}\text { Synchronous and } \\
\text { asynchronous }\end{array}$ & $\begin{array}{l}\text { Synchronou } \\
\text { s }\end{array}$ & Asynchronous & $\begin{array}{l}\text { Asynchronou } \\
\text { S }\end{array}$ \\
\hline $\begin{array}{l}\text { Resistance to } \\
\text { Subject } \\
\text { variability }\end{array}$ & $\begin{array}{l}\text { High } \\
\text { variability }\end{array}$ & $\begin{array}{l}\text { High } \\
\text { variability }\end{array}$ & $\begin{array}{l}\text { High } \\
\text { variability }\end{array}$ & $\begin{array}{l}\text { High } \\
\text { variability }\end{array}$ & Minimumvariability & $\begin{array}{l}\text { High } \\
\text { variability }\end{array}$ & $\begin{array}{l}\text { Minimum } \\
\text { variability }\end{array}$ & $\begin{array}{l}\text { Minimum } \\
\text { variability }\end{array}$ \\
\hline $\begin{array}{l}\text { Effect of } \\
\text { emotion }\end{array}$ & High effect & High effect & High effect & High effect & Minimum effect & High effect & $\begin{array}{l}\text { Minimumeffe } \\
\text { ct }\end{array}$ & $\begin{array}{l}\text { Minimum } \\
\text { effect }\end{array}$ \\
\hline $\begin{array}{l}\text { Level of } \\
\text { fatigue }\end{array}$ & $\begin{array}{l}\text { Maximum } \\
\text { fatigue }\end{array}$ & $\begin{array}{l}\text { Maximum } \\
\text { fatigue }\end{array}$ & $\begin{array}{l}\text { Maximum } \\
\text { fatigue }\end{array}$ & $\begin{array}{l}\text { Maximum } \\
\text { fatigue }\end{array}$ & Minimumfatigue & $\begin{array}{l}\text { Minimum } \\
\text { fatigue }\end{array}$ & $\begin{array}{l}\text { Minimum } \\
\text { fatigue }\end{array}$ & $\begin{array}{l}\text { Minimum } \\
\text { fatigue }\end{array}$ \\
\hline Easiness & Difficult & Difficult & Difficult & Difficult & Easy & Easy & Easy & Easy \\
\hline $\begin{array}{l}\text { No. of } \\
\text { commands }\end{array}$ & $\begin{array}{l}\text { Large } \\
\text { number of } \\
\text { commands }\end{array}$ & $\begin{array}{l}\text { Large } \\
\text { number of } \\
\text { commands }\end{array}$ & $\begin{array}{l}\text { Large } \\
\text { number of } \\
\text { commands }\end{array}$ & $\begin{array}{l}\text { Large } \\
\text { number of } \\
\text { commands }\end{array}$ & $\begin{array}{l}\text { Small number of } \\
\text { commands }\end{array}$ & $\begin{array}{l}\text { Large } \\
\text { number of } \\
\text { commands }\end{array}$ & $\begin{array}{l}\text { Small number } \\
\text { of commands }\end{array}$ & $\begin{array}{l}\text { Small } \\
\text { number of } \\
\text { commands }\end{array}$ \\
\hline $\begin{array}{l}\text { Command } \\
\text { reliability }\end{array}$ & $\begin{array}{l}\text { Highly } \\
\text { Reliable }\end{array}$ & $\begin{array}{l}\text { Highly } \\
\text { reliable }\end{array}$ & $\begin{array}{l}\text { Highly } \\
\text { reliable }\end{array}$ & $\begin{array}{l}\text { Highly } \\
\text { reliable }\end{array}$ & Low reliability & $\begin{array}{l}\text { Highly } \\
\text { reliable }\end{array}$ & $\begin{array}{l}\text { Low } \\
\text { reliability }\end{array}$ & $\begin{array}{l}\text { Highly } \\
\text { reliable }\end{array}$ \\
\hline $\begin{array}{l}\text { Controllabilit } \\
\mathbf{y}\end{array}$ & Less & Less & Less & Less & High & High & High & High \\
\hline $\begin{array}{l}\text { Information } \\
\text { transfer rate } \\
\text { (bits/min) }\end{array}$ & 30 to 100 & 25 & 1.12 to 2.08 & 20 to 25 & 3 to 35 & 5 to 12 & - & $\begin{array}{l}\text { As high as } \\
\text { possible }\end{array}$ \\
\hline $\begin{array}{l}\text { System } \\
\text { Accuracy }\end{array}$ & $95.5 \%$ & 70 to $80 \%$ & $\begin{array}{l}64.67 \text { to } \\
84.33 \%\end{array}$ & 80 to $95 \%$ & 90 to $100 \%$ & 65 to $90 \%$ & 70 to $90 \%$ & High \\
\hline $\begin{array}{l}\text { Preparation } \\
\text { time }\end{array}$ & $5 \mathrm{~min}$ & 5 days & $\begin{array}{l}10 \text { to } 15 \\
\min \end{array}$ & $5 \mathrm{~min}$ & 2 to 20 weeks & $\begin{array}{l}5 \text { hrs to few } \\
\text { weeks }\end{array}$ & $\begin{array}{l}150 \mathrm{sec} \text { to few } \\
\min \end{array}$ & Minimum \\
\hline $\begin{array}{l}\text { Number of } \\
\text { Choices }\end{array}$ & High & Average & Average & High & Low & Low & Average & High \\
\hline $\mathbf{S} / \mathbf{N}$ & High & Average & Average & Low & High & Average & Low & High \\
\hline Cost Effective & Yes & Average & Yes & Average & No & Yes & Average & Yes \\
\hline $\begin{array}{l}\text { Possibility } \\
\text { of triggering } \\
\text { device by } \\
\text { mistake }\end{array}$ & $\begin{array}{l}\text { Minimal } \\
\text { possibility }\end{array}$ & $\begin{array}{l}\text { Minimal } \\
\text { possibility }\end{array}$ & $\begin{array}{l}\text { Minimal } \\
\text { possibility }\end{array}$ & $\begin{array}{l}\text { Minimal } \\
\text { possibility }\end{array}$ & Moderate possibility & $\begin{array}{l}\text { Moderate } \\
\text { possibility }\end{array}$ & $\begin{array}{l}\text { Moderate } \\
\text { possibility }\end{array}$ & Minimum \\
\hline Stability & $\begin{array}{l}\text { Moderately } \\
\text { stable }\end{array}$ & $\begin{array}{l}\text { Moderately } \\
\text { stable }\end{array}$ & $\begin{array}{l}\text { Low } \\
\text { stability }\end{array}$ & $\begin{array}{l}\text { Moderately } \\
\text { stable }\end{array}$ & Highly stable & $\begin{array}{l}\text { Highly } \\
\text { stable }\end{array}$ & Highly stable & Highly stable \\
\hline
\end{tabular}




\begin{tabular}{|l|l|l|l|l|l|l|l|}
\hline & & & & & & \\
\hline Errors & 10 to $20 \%$ & - & 2 to $5 \%$ & $5 \%$ & 10 to $11 \%$ & 10 to $30 \%$ & - \\
\hline Classes & Multi class & Multi class & Single class & Multi class & Multi class & Multi class & Multi class \\
\hline
\end{tabular}

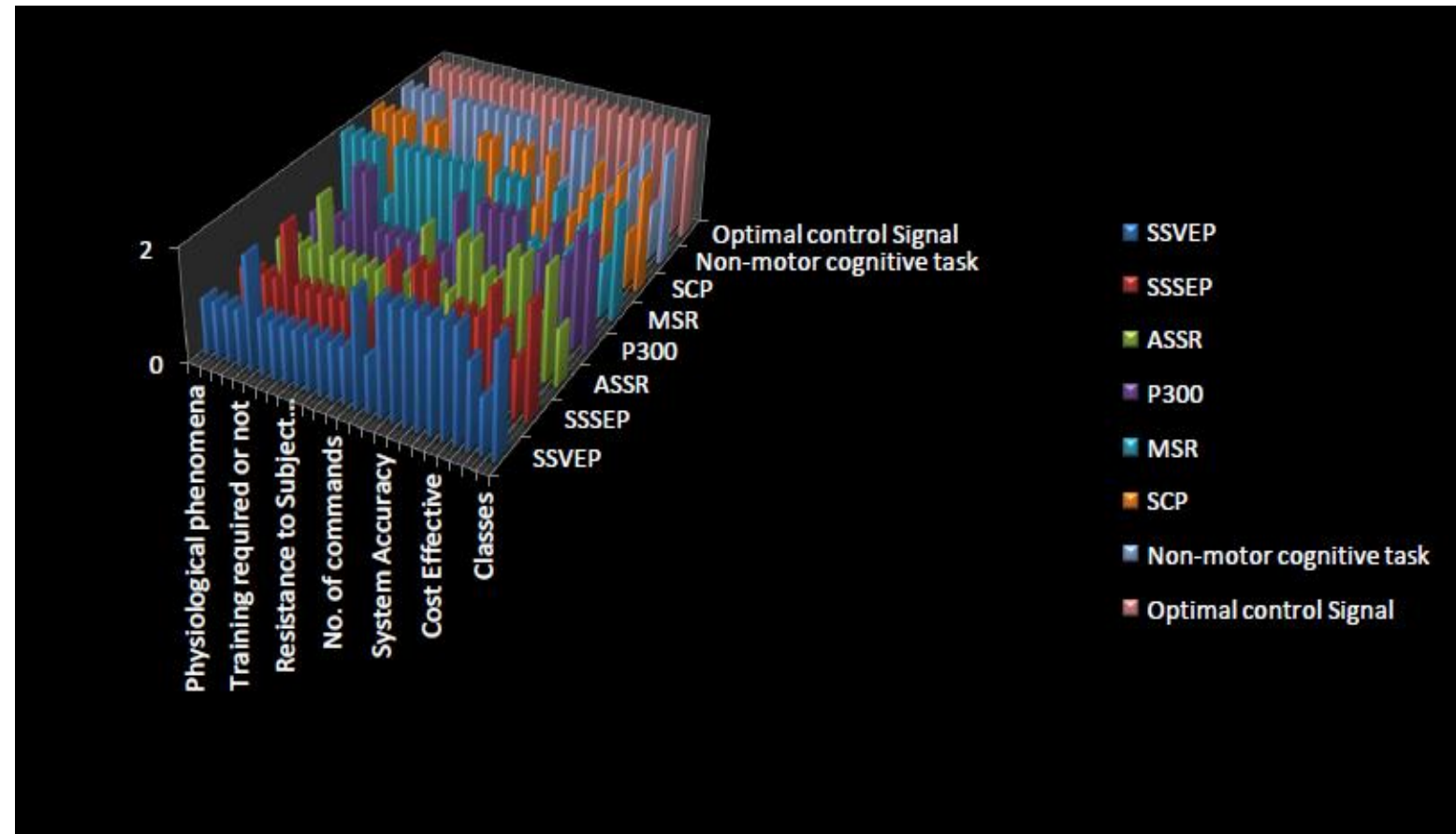

Fig. 3: A 3D column graph is prepared by representing the ideal considerations as 2 units and other practical considerations as 1 unit and 1.5 units depending on the degree of nearness to the ideal value.

\section{Conclusion}

BCI control signals conferred in this paper are already been utilized in diverse applications but nobody have donecomparative analysis of these control signals till date. It is quite tricky to select the optimal control signal as all these signals have their advantages and disadvantages. SSVEP, SSSEP, ASSR and P300 have the advantage that they don't demand subject training however external stimuli is mandatory which makes the process very tiring for the subject. On the other hand, Motor/Sensorimotor rhythms,Non-motor cognitive task signals and SCPs are more comfortable and come naturally to the subject.These processes don't demand external stimuli however they require longer time period for training.

With the advancement in signal processing methods one can expect a decrease in subject's training requirements or even its eradication in near future.

In this work we have initially suggested the three major conditions for a Casual BCI to be user friendly namely convenience and comfort of the user, stable system performance and cost factor. Thereafter, we evaluated the major conditions necessary for a control signal to be an optimal control signal for a BCI and enlisted three conditions which states that the control signal should be precisely characterized, readily modulated or translated as well as should be consistent and reliably detected.

Taking into account the necessary conditions of both the cases of "user friendly" Casual BCI and optimal control signal of a BCI we formulated a chart with 26 considerations. The chart compares the present day BCI control signals such as SSVEP, SSSEP, ASSR, P300, Motor and sensory motor rhythms, SCP, Non motor cognitive task signals with the ideal optimal control signal on the basis of these 26 considerations.

A 3D column graph is prepared by considering the ideal considerations having a weighted value of 2 units and other practical considerations as 1 unit and 1.5 units depending on the degree of nearness to the ideal value as represented in the Fig 3. For example the $24^{\text {th }}$ consideration is "Stability" and the Optimal signal should have value for this consideration as "Highly Stable", so while preparing the graph the control signals having the "Highly stable value" will have the weighted value of 2 units where as "Moderately stable" value will have 1.5 units and "Low stability" value will have 1 unit as weighted values. Hence the every control signals would be assigned weighted values for every consideration in comparison with the considerations of optimal control signal. Hence a curve could be drawn where one could very easily identify the curve which has maximum degree of closeness to the optimal control signal curve, which is a straight line. Thus, after comparison of various control signal curves with the ideal curve (straight line) of the optimal control signal we conclude that Motor and Sensorimotor rhythm's curve matches the ideal curve to the maximum and hence it is the best possible control signal for a user friendly Casual BCI in the present scenario. Howsoever scope for improvisation is still there as one ballpark figure in this work is the comparison between control signal considerations as they are not tested undersimilar circumstances, i.e. with same user, same acquisition protocols etc. Nevertheless with the advancement of BCI studies and the supporting disciplines, one can anticipate an ideal control signal in the near future.

\section{References}

[1] Niedermeyer, Ernst, and FH Lopes da Silva, eds. Electroencephalography: basic principles, clinical applications, and related fields. Lippincott Williams \& Wilkins, 2005.

[2] Curran, Eleanor A., and Maria J. Stokes. "Learning to control brain activity: a review of the production and control of EEG components for driving brain-computer interface (BCI) systems." Brain and cognition 51.3 (2003): 326-336 
[3] Wolpaw, Jonathan R., et al. "Brain-computer interfaces for communication and control." Clinical neurophysiology 113.6 (2002): 767-791

[4] Lalor, Edmund C., et al. "Steady-state VEP-based brain-computer interface control in an immersive 3D gaming environment." EURASIP Journal on Advances in Signal Processing 2005.19 (2005): 706906.

[5] Gouy-Pailler, Cedric, et al. "Topographical dynamics of brain connections for the design of asynchronous brain-computer interfaces." Engineering in Medicine and Biology Society, 2007.EMBS 2007.29th Annual International Conference of the IEEE.IEEE, 2007.

[6] Muller-Putz, Gernot R., et al. "Steady-state somatosensory evoked potentials: suitable brain signals for brain-computer interfaces?." IEEE transactions on neural systems and rehabilitation engineering 14.1 (2006): 30-37.

[7] McMillan, Grant R., et al. "Direct brain interface utilizing selfregulation of steady-state visual evoked response (SSVER)." Proc. RESNA'95 Annu. Conf. Vol. 15. 1995.

[8] Touyama, Hideaki, and Michitaka Hirose. "Steady-state VEPs in CAVE for walking around the virtual world." International Conference on Universal Access in Human-Computer Interaction.Springer, Berlin, Heidelberg, 2007.

[9] Solis-Escalante, Teodoro, Gerardo Gabriel Gentiletti, and Oscar Yanez-Suarez. "Detection of steady-state visual evoked potentials based on the multisignal classification algorithm." 3rd International IEEE/EMBS Conference on Neural Engineering, 2007.CNE'07. 2007.

[10] Nicolas-Alonso, Luis Fernando, and Jaime Gomez-Gil. "Brain computer interfaces, a review." Sensors 12.2 (2012): 1211-1279.

[11] Silberstein, Richard B., and A. Pipingas. "Steady-state visually evoked potential topography during the Wisconsin card sorting test." Electroencephalography and Clinical Neurophysiology/Evoked Potentials Section 96.1 (1995): 24-35

[12] Zhu, Danhua, et al. "A survey of stimulation methods used in SSVEP-based BCIs." Computational intelligence and neuroscience 2010 (2010): 1.

[13] Regan, David. "Human brain electrophysiology: evoked potentials and evoked magnetic fields in science and medicine." (1989).

[14] Vialatte, François-Benoît, et al. "Steady-state visually evoked potentials: focus on essential paradigms and future perspectives." Progress in neurobiology 90.4 (2010): 418-438.

[15] Perlstein, William M., et al. "Steady-state visual evoked potentials reveal frontally-mediated working memory activity in humans." Neuroscience letters 342.3 (2003): 191-195.

[16] Gray, M., et al. "Cortical neurophysiology of anticipatory anxiety: an investigation utilizing steady state probe topography (SSPT)." Neuroimage 20.2 (2003): 975-986.

[17] Giabbiconi, Claire Marie, et al. "Selective spatial attention to left or right hand flutter sensation modulates the steady-state somatosensory evoked potential." Cognitive brain research20.1 (2004): 58-66.

[18] Müller-Putz, Gernot. "New Concepts in Brain-Computer Communication: Use of Steady-State Somatosensory Evoked Potentials, User Training by Telesupport and Control of Functional Electrical Stimulation." (2004)

[19] Nangini, C., et al. "Magnetoencephalographic study of vibrotactile evoked transient and steady-state responses in human somatosensory cortex." Neuroimage 33.1 (2006): 252-262.

[20] Snyder, Abraham Z. "Steady-state vibration evoked potentials: description of technique and characterization of responses." Electroencephalography and Clinical Neurophysiology/Evoked potentials Section 84.3 (1992): 257-268.

[21] Muller, G. R., ChNeuper, and GertPfurtscheller. ",Resonance-like "frequencies of sensorimotor areas evoked by repetitive tactile stimulation-resonan insensomotorischenarealen, evoziertdurchrhythmischetaktile stimulation." BiomedizinischeTechnik/Biomedical Engineering46.7-8 (2001): 186-190.

[22] Tobimatsu, Shozo, You Min Zhang, and Motohiro Kato. "Steadystate vibration somatosensory evoked potentials: physiological characteristics and tuning function." Clinica neurophysiology 110.11 (1999): 1953-1958.

[23] Roß, Bernhard, et al. "A high-precision magnetoencephalographic study of human auditory steady-state responses to amplitudemodulated tones." The Journal of the Acoustical Society of America 108.2 (2000): 679-691.
[24] Ross, B., et al. "The effect of attention on the auditory steady-state response." Neurology \& clinical neurophysiology: NCN2004 (2004): 22-22

[25] Mäkelä, J. P., and R. Hari. "Evidence for cortical origin of the 40 $\mathrm{Hz}$ auditory evoked response in man." Electroencephalography and clinical neurophysiology 66.6 (1987): 539-546.

[26] Steriade, M., et al. "Fast oscillations (20-40 Hz) in thalamocortical systems and their potentiation by mesopontine cholinergic nuclei in the cat." Proceedings of the National Academy of Sciences 88.10 (1991): 4396-4400.

[27] Engelien, Almut, et al. "A combined functional in vivo measure for primary and secondary auditory cortices." Hearing research 148.1-2 (2000): 153-160.

[28] Galambos, Robert. "Tactile and auditory stimuli repeated at high rates (30-50 per $\mathrm{sec})$ produce similar event related potentials." Annals of the New York Academy of Sciences338.1 (1980): 722-726

[29] Pastor, Maria A., et al. "Activation of human cerebral and cerebellar cortex by auditory stimulation at $40 \mathrm{~Hz}$." Journal of Neuroscience 22.23 (2002): 10501-10506.

[30] Picton, Terence W., et al. "Potentials evoked by the sinusoidal modulation of the amplitude or frequency of a tone." The Journal of the Acoustical Society of America 82.1 (1987): 165-178.

[31] Stapells, David R., Scott Makeig, and Robert Galambos. "Auditory steady-state responses: threshold prediction using phase coherence." Clinical Neurophysiology 67.3 (1987): 260-270.

[32] Roß, Bernhard, Terence W. Picton, and Christo Pantev. "Temporal integration in the human auditory cortex as represented by the development of the steady-state magnetic field." Hearing research 165.1-2 (2002): 68-84.

[33] Farwell, Lawrence Ashley, and Emanuel Donchin. "Talking off the top of your head: toward a mental prosthesis utilizing event-related brain potentials." Electroencephalography and clinical Neurophysiology 70.6 (1988): 510-523

[34] Polich, John, Patricia Crane Ellerson, and Jill Cohen. "P300, stimulus intensity, modality, and probability." International Journal of Psychophysiology 23.1-2 (1996): 55-62.

[35] Ravden, Daran, and John Polich. "On P300 measurement stability: habituation, intra-trial block variation, and ultradian rhythms." Biological psychology 51.1 (1999): 59-76.

[36] Pfurtscheller, Gert, and Christa Neuper. "Motor imagery and direct brain-computer communication." Proceedings of the IEEE 89.7 (2001): 1123-1134.

[37] Blankertz, Benjamin, et al. "Neurophysiological predictor of SMRbased BCI performance." Neuroimage 51.4 (2010): 1303-1309.

[38] Jeannerod, Marc. "Mental imagery in the motor context." Neuropsychologia 33.11 (1995): 1419-1432.

[39] Pfurtscheller, Gert, et al. "EEG-based discrimination between imagination of right and left hand movement." Electroencephalography and clinical Neurophysiology 103.6 (1997): 642-651.

[40] Birbaumer, Niels, et al. "Slow potentials of the cerebral cortex and behavior." Physiological reviews 70.1 (1990): 1-41.

[41] Birbaumer, Niels, et al. "The thought translation device (TTD) for completely paralyzed patients." IEEE Transactions on rehabilitation Engineering 8.2 (2000): 190-193.

[42] Kleber, Boris, and NielsBirbaumer. "Direct brain communication: neuroelectric and metabolic approaches at Tübingen." Cognitive Processing 6.1 (2005): 65-74

[43] Keirn, Zachary A., and Jorge I. Aunon. "A new mode of communication between man and his surroundings." IEEE transactions on biomedical engineering 37.12 (1990): 1209-1214.

[44] Müller-Putz, Gernot R., et al. "Comparison of DFT and lock-in amplifier features and search for optimal electrode positions in SSVEP-based BCI." Journal of neuroscience methods 168.1 (2008): 174-181.

[45] Middendorf, Matthew, et al. "Brain-computer interfaces based on the steady-state visual-evoked response." IEEE transactions on rehabilitation engineering 8.2 (2000): 211-214.

[46] Müller-Putz, Gernot R., et al. "Steady-state visual evoked potential (SSVEP)-based communication: impact of harmonic frequency components." Journal of neural engineering 2.4 (2005): 123

[47] Kelly, Simon P., et al. "Visual spatial attention control in an independent brain-computer interface." IEEE Transactions on Biomedical Engineering 52.9 (2005): 1588-1596.

[48] Kelly, Simon P., et al. "Visual spatial attention tracking using highdensity SSVEP data for independent brain-computer communication." IEEE Transactions on Neural Systems and Rehabilitation Engineering 13.2 (2005): 172-178 
[49] Lalor, E., et al. "Brain computer interface based on the steady-state VEP for immersive gaming control." BiomedizinscheTecknik 49.1 (2004): 63-64

[50] Sutter, Erich E. "The brain response interface: communication through visually-induced electrical brain responses." Journal of Microcomputer Applications 15.1 (1992): 31-45.

[51] Cheng, Ming, et al. "Design and implementation of a braincomputer interface with high transfer rates." IEEE transactions on biomedical engineering 49.10 (2002): 1181-1186.

[52] Nielsen, Kim Dremstrup, Alvaro Fuentes Cabrera, and Omar Feix do Nascimento. "EEG based BCI-towards a better control. Braincomputer interface research at Aalborg University." IEEE Transactions on Neural Systems and Rehabilitation Engineering 14.2 (2006): 202-204.

[53] Hill, N. Jeremy, et al. "An auditory paradigm for brain-computer interfaces." Advances in neural information processing systems. 2005.

[54] Donchin, Emanuel, Kevin M. Spencer, and RanjithWijesinghe "The mental prosthesis: assessing the speed of a P300-based braincomputer interface." IEEE transactions on rehabilitation engineering 8.2 (2000): 174-179.

[55] Glover, Andrew A., et al. "P300-like potentials in the norma monkey using classical conditioning and an auditory 'oddball'paradigm." Electroencephalography and Clinical Neurophysiology/Evoked Potentials Section 65.3 (1986): 231-235.

[56] Röder, Brigitte, et al. "Event-related potentials during auditory and somatosensory discrimination in sighted and blind human subjects." Cognitive Brain Research 4.2 (1996): 77-93.

[57] Miltner, Wolfgang, Wolfgang Larbig, and Christoph Braun. "Biofeedback of somatosensory event-related potentials: can individual pain sensations be modified by biofeedback-induced self-control of event-related potentials?." Pain 35.2 (1988): 205213.

[58] Sommer, Werner, and Stefan Schweinberger. "Operan conditioning of P300." Biological psychology 33.1 (1992): 37-49.

[59] Sugiarto, Indar. "Robust visual stimulator for P300BCI." Instrumentation, Communications, Information Technology, and Biomedical Engineering (ICICI-BME), 2009 International Conference on.IEEE, 2009.

[60] Hwang, Han-Jeong, Kiwoon Kwon, and Chang-Hwang Im. "Neurofeedback-based motor imagery training for brain-computer interface (BCI)." Journal of neuroscience methods179.1 (2009): 150-156.

[61] Wolpaw, Jonathan R., Dennis J. McFarland, and Theresa M. Vaughan. "Brain-computer interface research at the Wadsworth Center." IEEE Transactions on Rehabilitation Engineering 8.2 (2000): 222-226

[62] Blankertz, Benjamin, et al. "The Berlin Brain-Computer Interface: Accurate performance from first-session in BCI-naive subjects." IEEE Trans Biomed Eng 55.10 (2008): 2452-2462.

[63] Pfurtscheller, Gert, et al. "Graz-BCI: state of the art and clinica applications." IEEE Transactions on neural systems and rehabilitation engineering 11.2 (2003): 1-4

[64] McFarland, D. J., et al. "EEG-based brain-computer interface communication effect of target number and trial length on information transfer rate." SocNeurosciAbstr 2000b. Vol. 26. 2000.

[65] Hinterberger, Thilo, et al. "Brain-computer communication and slow cortical potentials." IEEE Transactions on Biomedical Engineering 51.6 (2004): 1011-1018.

[66] Kaiser, Jochen, et al. "Self-initiation of EEG-based communication in paralyzed patients." Clinical Neurophysiology 112.3 (2001): 551-554

[67] Neumann, Nicola, and NielsBirbaumer. "Predictors of successful self control during brain-computer communication." Journal of Neurology, Neurosurgery \& Psychiatry 74.8 (2003): 1117-1121.

[68] Millan, Jose del R., et al. "Local neural classifier for EEG-based recognition of mental tasks." ijcnn. IEEE, 2000.

[69] Besserve, Michel, Line Garnero, and Jacques Martinerie. "De l'estimation à la classification des activitéscorticales.Uneapproche par sélection de variables pour les Interfaces Cerveau Machine." $21^{\circ}$ Colloque GRETSI, Troyes, FRA, 11-14 septembre 2007. GRETSI, Grouped'Etudes du Traitement du Signal et des Images, 2007

[70] Chiappa, Silvia, and SamyBengio. HMM and IOHMM modeling of EEG rhythms for asynchronous BCI systems. No. EPFL-REPORT82978.IDIAP, 2003

[71] Anderson, Charles W., Erik A. Stolz, and SanyogitaShamsunder. "Multivariate autoregressive models for classification of spontaneous electroencephalographic signals during mental tasks." IEEE Transactions on Biomedical Engineering 45.3 (1998): 277-286.

[72] Millan, Jdel R., and JosepMouriño. "Asynchronous BCI and local neural classifiers: an overview of the adaptive brain interface project." IEEE Transactions on Neural Systems and Rehabilitation Engineering 11.2 (2003): 159-161.

[73] del R Millan, Jose, et al. "A local neural classifier for the recognition of EEG patterns associated to mental tasks." IEEE transactions on neural networks 13.3 (2002): 678-686.

[74] Penny, William D., and Stephen J. Roberts. "EEG-based communication via dynamic neural network models." Proc. Int. Joint Conf. on Neural Networks. 1999.

[75] Penny, William D., et al. "EEG-based communication: a pattern recognition approach." IEEE transactions on Rehabilitation Engineering 8.2 (2000): 214-215.

[76] Curran, Eleanor, et al. "Cognitive tasks for driving a braincomputer interfacing system: a pilot study." IEEE Transactions on Neural Systems and Rehabilitation Engineering 12.1 (2004): 48-54.

[77] Birbaumer, Niels, et al. "EEG and slow cortical potentials in anticipation of mental tasks with different hemispheric involvement." Biological Psychology 13 (1981): 251-260. 